\title{
Current Concepts of Starch Structure and Its Impact on Properties ${ }^{\dagger}$
}

\author{
David R. LINEBACK \\ Department of Food Science, North Carotina State University \\ (Raleigh, North Carolina, 27695-7624, U.S.A.)
}

Received November 15, 1985

\section{INTRODUCTION}

The structure of starch has been the subject of many investigations and much speculation. Determination of a unique structure is made infinitely complicated by the fact that starch is composed of two different polymers organized in some manner into a granule. Chemical methods of structure determination cannot be definitively used because of the lack of recognition points in the component polymers amylose and amylopectin. The two polymers are homoglucans with only two types of chain linkage, the $\alpha$-D-(1-4) of the main chain with occasional $\alpha$-D-(1-6) branch points.

Starches are widely used in industrial and food applications. The diversity of uses depends on differences in physical and functional properties of starches from different sources or those which have been modified in a selected manner. These functional differences must, in some manner, be related to the structure of the starches-granule, amylose or amylopectin. This relationship is not well understood and is the subject of much interest, speculation and discussion.

We became interested in the relationship between structure and functionality of wheat starches in the early 1970 's. Harris ${ }^{1)}$ and Sandstedt ${ }^{2)}$ found that rice, corn, waxy maize and potato starches do not have the breadmaking quality that wheat starch has. This was confirm.

Presented at the annual meeting of the Japanese Society of Starch Science, Osaka City University, Osaka, Japan, October 3, 1985. ed by Hoseney et al..$^{32}$ who also reported that rye and barley starches nearly equal wheat starch in breadmaking quality. Prime starches from hard red spring wheats, hard red winter wheats, soft white wheat and soft red wheat had essentially equal loaf volume and crumb characteristics in reconstitution studies. ${ }^{3)}$ However, prime starch from durum wheat produced a lower loaf volume, while that from club wheat produced a higher loaf volume than the control starch from a hard red winter wheat.

Are these observations due to differences in the structures of the amylose and amylopectin components of these wheat starches? Are they due to differences in the structure and organization of the starch granule? This presentation will attempt to briefly summarize our current understanding of the structure of amylose, amylopectin and the starch granule and will focus very briefly on some questions concerning properties, such as gelatinization and retrogradation.

\section{PROPERTIES OF WHOLE GRANULE STARCHES}

Starch occurs as discrete granules whose size and shape vary depending on the botanical source (Table 1). Amylose and amylopectin content also vary. Most cereal starches contain 20 to $30 \%$ amylose. However, certain genetic variants, such as high-amylose maize and wrinkled-pea starch, contain 50 to $70 \%$ amylose. Waxy varieties of maize, barley and rice contain 1\% or less of amylose. The gelatinization temperature ranges of starches vary with the botanical source. All of these differences infer that the 
Table 1. Some properties of whole granular starches. ${ }^{a}$

\begin{tabular}{|c|c|c|c|c|}
\hline Source & $\begin{array}{c}\text { Gelatinization } \\
\text { temperature } \\
\text { range }\left({ }^{\circ} \mathrm{C}\right)\end{array}$ & Granule shape & $\begin{array}{c}\text { Granule } \\
\text { size }(n m)\end{array}$ & $\begin{array}{c}\text { Amylose } \\
\text { content }(\%)\end{array}$ \\
\hline Barley & $51-60$ & $\begin{array}{l}\text { Round or } \\
\text { elliptical }\end{array}$ & $\begin{array}{c}20-25 \\
2-6\end{array}$ & 22 \\
\hline Triticale & $55-62$ & Round & 19 & $23-24$ \\
\hline Wheat & $58-64$ & $\begin{array}{l}\text { Lenticular or } \\
\text { round }\end{array}$ & $\begin{array}{r}20-35 \\
2-10\end{array}$ & $26(23-27)$ \\
\hline Rye & $57-70$ & $\begin{array}{l}\text { Round or } \\
\text { lenticular }\end{array}$ & 28 & 27 \\
\hline Oats & $53-59$ & Polyhedral & $3-10$ & $23-24$ \\
\hline Potato & $59-68$ & Oval & $40(15-100)$ & 23 \\
\hline Corn & $62-72$ & $\begin{array}{l}\text { Round or } \\
\text { polyhedral }\end{array}$ & 15 & 28 \\
\hline Waxy maize & $63-72$ & Round & $15(5-15)$ & 1 \\
\hline Broad bean & $64-67$ & Oval & 30 & 24 \\
\hline Sorghum & $68^{-78}$ & Round & 35 & $25(23-28)$ \\
\hline Rice & $68-78$ & Polygonal & $3-8$ & $\begin{array}{l}17-19 \text { (japonica) } \\
21-21 \text { (indica) }\end{array}$ \\
\hline High amylose maize & $67-80$ & $\begin{array}{l}\text { Round, irregular } \\
\text { sausage-shaped }\end{array}$ & 25 & 52 \\
\hline
\end{tabular}

a From Lineback. ${ }^{4)}$

starches differ to some extent in structure and/ or organization of the components and granule.

A third component, intermediate material, is present in many starches, particularly those with high-amylose content. Approximately 5 to $10 \%$ of this material is reported for most cereal starches. However, smooth-pea starch (33\% amylose) contains $0.4 \%$ intermediate material, while wrinkled-pea starch ( $71 \%$ amylose) contains $18.9 \%$ of this material. ${ }^{5)}$ The intermediate material does not fit the normal description of amylose or amylopectin and its structure is not well characterized. Colonna and Mercier ${ }^{5)}$ have shown that the intermediate fraction from wrinkled-pea starch is composed of the same short (d. p. 15) and long (d. p. 45) linear chains as amylopectin, but the ratio of short to long chains was 3.6 for the intermediate fraction compared to 9.6 for wrinkled-pea and 8.1 for smooth-pea amylopectins.

\section{STRUCTURE OF AMYLOSE}

For many years amylose was considered to be a linear polymer. This view was primarily based on the complete hydrolysis of amylose by the preparations of $\beta$-amylase which were available then. When crystalline $\beta$-amylase became available, studies revealed that crystalline sweet potato $\beta$-amylase hydrolyzed about $70 \%$ of potato amylose to maltose. ${ }^{6)}$ This inferred the presence of a barrier to the action of $\beta$-amylase in amylose.

When potato amylose was treated with yeast isoamylase, free of $\alpha$-amylase, the $\beta$-amylolysis limit was increased to $90 \%$. Quantitative conversion of potato amylose to maltose was obtained when amylose was simultaneously incubated with pullulanase and $\beta$-amylase. ${ }^{7)}$ These results are best explained if a limited amount of long-chain branching is present in amylose. The failure of pullulanase and $\beta$-amylase to completely convert amylose to maltose, when used sequentially, may have been due to retrogradation of the amylose when incubated with pullulanase. $^{8)}$

Hizukuri et $a .^{9)}$ developed sensitive methods for determining the reducing and non-reducing residues of amylose and its degradation products. From such data, they showed the presence of 9 to 20 branch points (chains) per molecule of amylose(Table 2). Lii et al. ${ }^{10)}$ found that amyloses isolated from mung bean, pea, cassava, corn and sweet potato starches had 
Table 2. Properties of amylose. ${ }^{a}$

\begin{tabular}{lccccc}
\hline Source & $\begin{array}{c}\text { D. p./red. } \\
\text { residue }\end{array}$ & $\begin{array}{c}\text { D. p./non-red. } \\
\text { residue }\end{array}$ & $\begin{array}{c}\text { Chain } \\
\text { number }\end{array}$ & $\begin{array}{c}\text { Iodine } \\
\text { affinity } \\
(\mathrm{g} / 100 \mathrm{~g})\end{array}$ & $\begin{array}{c}\beta \text {-Amylolysis } \\
\text { limit(\%) }\end{array}$ \\
\hline Potato & 6,340 & 520 & 12.2 & 19.6 & 68 \\
Potato ${ }^{\mathrm{b}}$ (Kenebec) & 4,850 & 510 & 9.5 & 20.1 & 88 \\
Tapioca & 3,390 & 170 & 20.0 & 19.0 & 64 \\
Kuzu & 1,590 & 180 & 9.1 & 19.9 & 76 \\
\hline
\end{tabular}

a From Hizukuri et al. b Prepared from starch prepared in a laboratory.

average chain lengths varying from 936 to 1,909 glucose units. These values are higher than the values reported for the amyloses in Table 2, but were determined using different methods. Colonna and $\mathrm{Mercier}^{5)}$ reported that the amylose from wrinkled-pea starch is composed of 2 to 3 chains, while that from smooth-pea starch averages 3.2 chains. These authors interpret the data available on the branching of amylose to be in accord with a branched structure involving 2 to 4 chains per thousand glucose units. This is consistent with a structure which contains a limited number of branches containing long side chains.

One must be extremely cautious in interpreting data relating to the structure of amylose, because of limitations in the method of isolation and/or the nature of the sample used. It is likely that isolated amylose is a mixture of components with different structures, i.e. a mixture of linear and branched molecules, unless special precautions are used. Greenwood and Thom- son $^{7)}$ found that low molecular weight linear amylose is leached from starch granules at low temperatures (Table 3). As the extraction temperature is increased, the $\beta$-amylolysis limit of the extracted material decreases, indicating the presence of branches. Ghiasi et al. ${ }^{11)}$ reported that the material preferentially leached from wheat starch at $75^{\circ} \mathrm{C}$ was amylose, based on a high $(18.5 \%)$ iodine affinity. As the temperature of extraction increased, the iodine affinity of the leached material decreased indicating an increased amount of branching. Colonna and Mercier ${ }^{5)}$ found that only $10 \%$ of amylose and intermediate material are extractable by leaching wrinkled-pea starch granules. This material was different from that of total amylose on gel filtration. Without special precautions, the amylose used for structural studies must be considered a mixture of polymers.

We are currently studying the branched nature of selected wheat starch amyloses with Dr. S. Kobayashi. This work has been delayed by

Table 3. Properties of amylose components obtained on successive leaching of whole starch granules. ${ }^{a}$

\begin{tabular}{cccc} 
Starch & Procedure & $\begin{array}{c}\text { Amylose } \\
\text { extracted }(\%)^{\circ}\end{array}$ & $\begin{array}{c}\beta \text {-Amylolysis } \\
\text { limit }(\%)\end{array}$ \\
\hline Barley & $70^{\circ} \mathrm{C}$ leach & 26 & 96 \\
& $80^{\circ} \mathrm{C}$ leach & 15 & 74 \\
& $90^{\circ} \mathrm{C}$ leach & 20 & 65 \\
& Dispersion of residue & 39 & 62 \\
Pea(smooth-seeded) & $70^{\circ} \mathrm{C}$ leach & 2 & 88 \\
& $80^{\circ} \mathrm{C}$ leach & 3 & 83 \\
& $90^{\circ} \mathrm{C}$ leach & 4 & 80 \\
\hline
\end{tabular}

a Adapted from GREENWOOD and THOMSON, ${ }^{\text {") }}$

b Calculated from iodine-binding capacity measurements.

c Followed by addition of thymol. 
the discovery of contaminating glucosidases in commercial $\beta$-amylase preparations and of $\beta$ amylase in commercial pullulanase preparations used for the structural studies. Attempts at removal or neutralization of these contaminating activities are now underway.

The structure of amylose may be close to being known to the extent possible with current methodologies, samples and the inherent nature of amylose. It may not be feasible to define the "fine" structure to any greater extent than is now becoming known.

\section{AMYLOPECTIN STRUCTURE}

As the major component of most normal starches, the structure of amylopectin has received much study. A number of structures have been proposed since the Meyer "tree" formula of 1940. ${ }^{12)}$ The currently accepted structural models are those derived from the cluster models of Nikuni ${ }^{13,14)}$ and French ${ }^{15)}$ (Fig. 1a). A similar model (Fig. 1b) was proposed by Robin et al. ${ }^{16)}$ from data derived from the sequential treatment with debranching enzymes and $\beta$-amylase of potato amylopectin, its $\beta$-limit dextrin or the amylodextrin obtained by acid treatment of the starch at about room temperature. An important feature of this model was the presence in the debranched amylopectin of three chain populations with chain lengths of 15 to 20,45 and about 60 (the smallest amount). Similar chain lengths and distributions have been reported for a number of debranched amylopectins from other sources.

A critical examination of the ratio of $A$ and $B$ chains in amylopectin revealed a value of about $1: 1,{ }^{17)}$ rather than about $2: 1$ as first reported by Marshall and Whelan. ${ }^{18)} \mathrm{A}$ model compatible with this observation and with the changes occurring during amylolysis of amylopectin has been proposed (Fig. 1c).

All of these structures include the concept that the branch points are arranged in clusters. The structure accounts for crystalline and amorphous regions in starch. The branch points are located in less-organized amorphous regions, while the chains can associate into crystalline regions. This behavior is consistent with the acid degradation of starch to Nageli amylodex- trins. The crystalline amylodextrins have chain lengths of 14 to 16 units or dimensions of about $50 \AA$, similar to starch crystallites. These chains probably exist as double helices, but the extent and organization are not definitely known yet.

We have been interested in the question as to whether amylopectins from different wheat varieties and classes have the same structure or whether differences in structure could be related to differences in functionality. Current data appear to indicate that amylopectins from different wheat starches have similar structures. Using $\beta$-limit dextrins and phosphorylase, $\beta$ limit dextrins from several different wheat starches, we found ${ }^{19)}$ that the wheat starches studied appeared to have definite, but minor, differences in structures with the amylopectins having $\mathrm{A}$ chain to B-chain ratios ranging from 1.2 to 2.1. However, the enzymic method, coupled with the reducing-value measurement, used have been questioned ${ }^{17,20)}$ indicating that the differences we observed probably were not significant. Using more sensitive, more reproducible methods, amylopectins from ten varieties (five classes) of wheat were examined. ${ }^{21)}$ Using a high-performance size-exclusion chromatographic (HPSEC) method developed to separate and monitor starch components, ${ }^{22)}$ amylopectin samples were isolated which contained a single polysaccharide peak with similar retention time and peak shape (Fig. 2). Debranching of the amylopectins with isoamylase resulted in four carbohydrate components (Fig. 3), shown to be linear by complete conversion to maltose with $\beta$-amylase. The average chain lengths for the four components were $86,39,19$ and 12 , representing $4,19,31$ and $46 \%$ of the total peak area, respectively. The wheat amylopectins studied were identical in their debranching patterns and component proportions, indicating no detectable differences in their structure. Thus, it is unlikely that differences in functionality of different wheat starches can be attributed to differences in the structure of the amylopectin components.

It seems likely that we have gone about as far as we can in determining the "fine" structure of amylopectin. The cluster model with an Achain to B-chain ratio of from about $1: 1$ to 1.5:1 accounts for the enzymatic degradation of amylopectin and its properties. An inherent 
(a) French "clusler" model

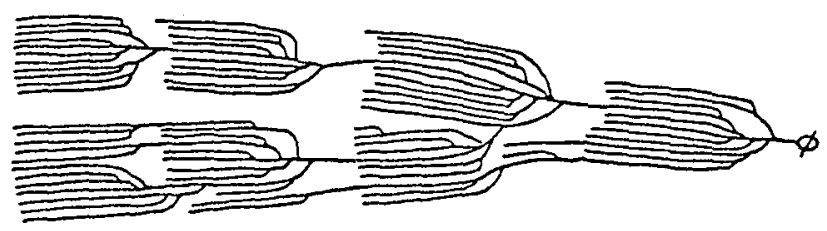

(b) Robln "cluster" model

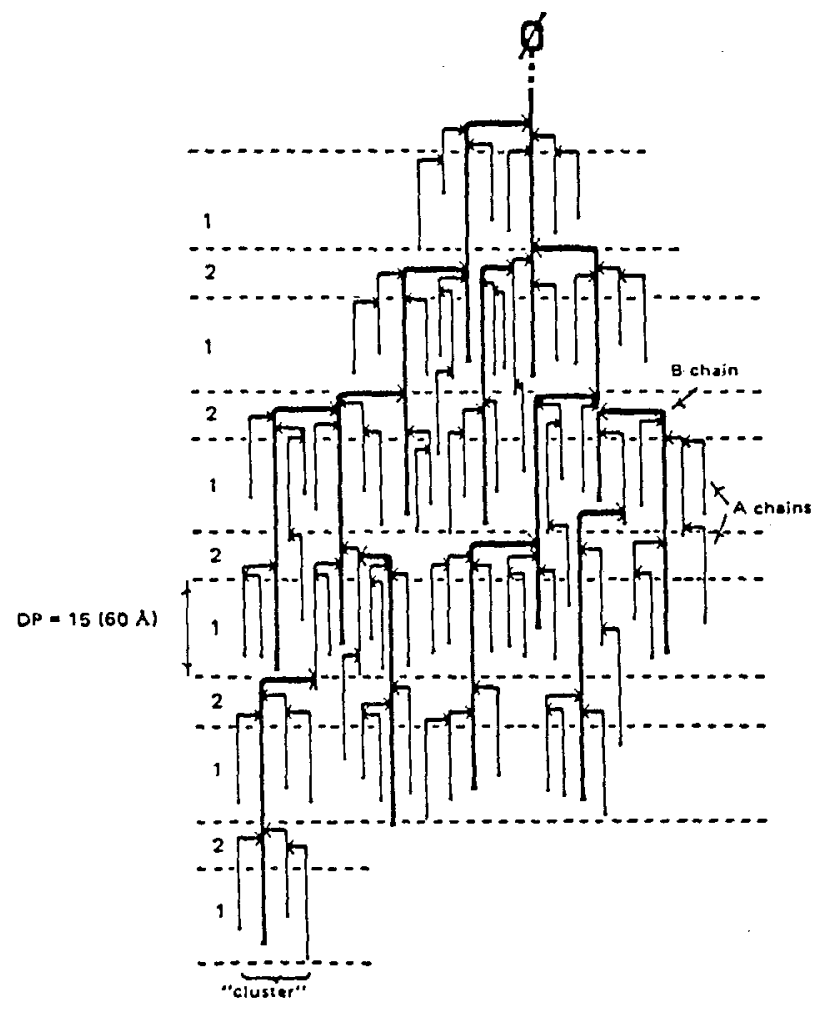

(c) Manners and Matheson "clusler" model

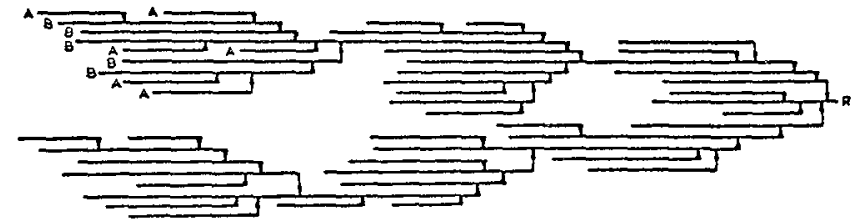

Fig. 1. Structural models of amylopectin as proposed by French ${ }^{15)}$ (a), Robin et al. ${ }^{16)}$ (b), and Manners and Matheson ${ }^{17}$ (c).

Reproduced from D. J. Manners: Cereal Foods World, 30, 461 (1985). 


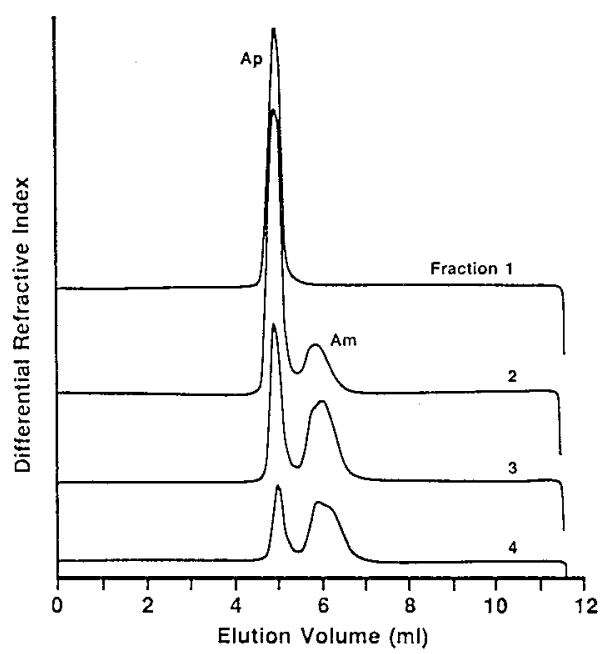

Fig. 2. Purity of fractions collected from preparative HPSEC eluate.

Ap, amylopectin; Am, amylose. Reproduced from Ref. 22).

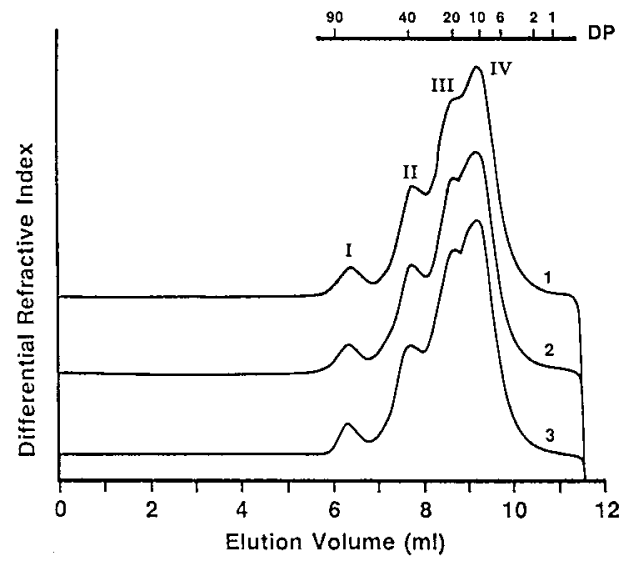

Fig. 3. Profiles of debranched Scout (1), Era (2) and Omar (3) amylopectins.

Reproduced from Ref. 22).

difficulty in determining the "fine" structure of amylopectin is its high molecular weight. There is no reason to assume that every amylopectin molecule is the same. Thus, we are forced to deal with the average of a mixture of closely similar polymers in any structural investigation. Furthermore, we cannot be certain that all chains are degraded to the same extent during enzyme treatment, particularly during the formation of limit dextrins. Some chains could be buried in the interior of the molecule and hence relatively inaccessible to enzymes under normal conditions.

\section{STARCH GRANULE STRUCTURE}

The last great bastion and challenge in starch structure determination is the starch granule and the organization of amylose and amylopectin within the granule. A trichitic model was first proposed for the starch granule in $1895 .{ }^{23)}$ That the structure contained a concentric ring-like organization was remarkable because the concept of high polymers had not been developed. Nor was it known that starch contained two polysaccharide components.

Nikuni proposed a model for the starch granule which incorporated the amylose and amylopectin components, including the appearance of concentric rings or shells (Fig. 4). ${ }^{13)}$ This model still serves well for our understanding of normal starches with a few minor modifications (Fig. 5). ${ }^{4)}$ This model incorporated the cluster concept of amylopectin. Amylose could exist in a random or helical configuration depending upon the presence of lipids, as occurs in most cereal starches. It is unlikely that the outer surface of the granule is smooth or uniform as drawn in Fig. 5, or as observed in scanning electron photomicrographs of starch granules. It is more likely that the surface observed is a boundary or organization with the appearance of a "hairy billard ball." Chains of amylose

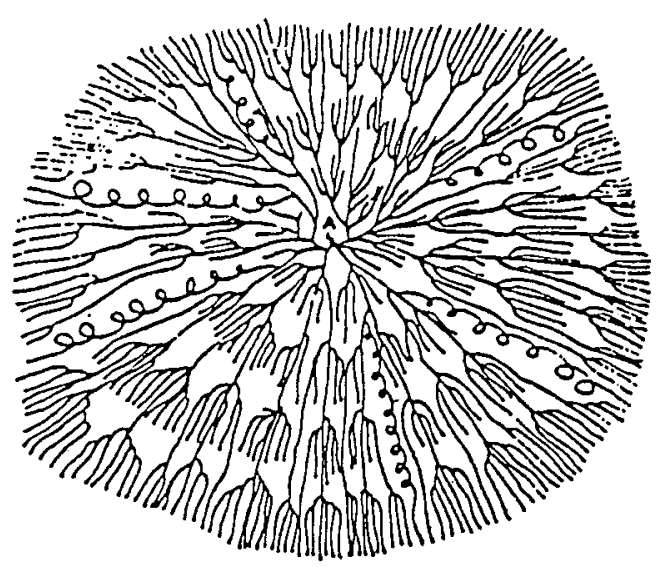

Fig. 4. A schematic model of a starch granule. Reproduced from Ref. 14). 


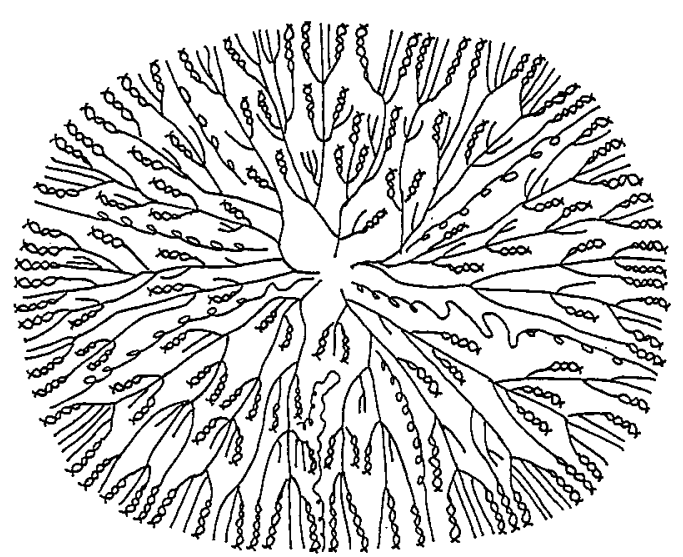

Fig. 5. Schematic of the organization (structure) of a starch granule.

Reproduced from Ref. 4).

and amylopectin of different lengths probably protrude through this area. This would agree with the concept of granule growth by apposition with the protruding chains available for elongation and subsequent branching.

Several features remain to be solved and these include:

1. How are the amylose and amylopectin components organized in the granule? The answer to this question must account for the leaching experiments in which linear amylose is obtained at lower temperatures with an increasing amount of branched-chain material obtained as the temperature is increased.

2. It has been shown that physical damage (by a micronising mill) of starch granules results in the extraction of amylopectin of low molecular weight with cold water. ${ }^{24 \nmid}$ Is the shear force and heat generation of such milling procedures sufficient to rupture (hydrolyze) covalent linkages in amorphous (crystalline) regions of the granule using the moisture present? Is the effect on hydrogen bonding, thereby loosening the structure? Or is there some special or unique feature in the organization/structure of the granule which contributes to this behavior?

3. How extensive is the formation of double helices among the chains of the amylopectin clusters? Are chains from adjacent molecules involved, interweaving the structure and adding some stabilizing force to the structure?

Kainuma $^{25)}$ and French ${ }^{26)}$ have proposed a

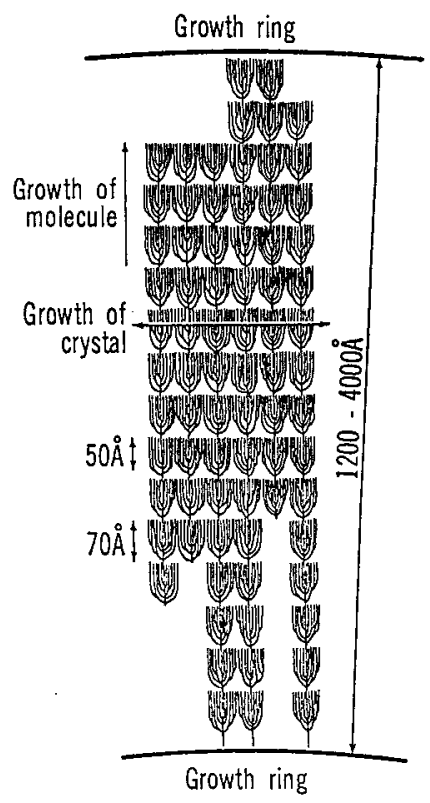

Fig. 6. Schematic representation of the arrangement of amylopectin molecules within a growth ring of waxy maize starch.

Reproduced from Ref. 26).

possible arrangement for the amylopectin chains in a waxy maize starch granule (Fig. 6). This model was based on electron microscopic studies coupled with previous data generated from the study of Nageli amylodextrins. Since the model was derived for a waxy starch, it does not readily appear how amylose can be incorporated into such a model for the case of a normal starch. Do the structures of the two types of starch differ completely, or is it in how the amylose is incorporated into the normal starch granule?

The structure and organization of the granules require much further investigation before any real clarity in our understanding of these features can occur. New, more sensitive techniques will need to be developed and applied to these questions. In many ways we are now limited by the availability of suitable, sensitive methods to generate the data required. The application of traditional techniques has furnished just about all that is possible from such methods. 


\section{EFFECTS OF STRUCTURE ON STARCH PROPERTIES}

Gelatinization is one of the most important and unique properties of starch granules. It is generally accepted that water first penetrates the amorphous regions initiating swelling and the loss of birefringence as the temperature is increased. With increasing temperature, thermal motion (increased kinetic energy of the molecules) and solvation lead to decreasing order and rupture of the crystalline regions with uncoiling of the double helices until, in dilute aqueous solutions at sufficiently high temperatures, the granule structure is disrupted nearly completely and a sol is obtained. However, if starch granules are heated at $50^{\circ} \mathrm{C}$ for $72 \mathrm{hr}$, gelatinization occurs at a higher temperature, but over a much narrower range, compared to untreated granules. ${ }^{27)}$ This annealing effect implies a higher extent of order. How does this occur in terms of granule structure? What is it about granule structure that causes starches from different botanical sources to have different gelatinization temperatures?

As starch is heated, an exudate (amylose) forms which has been reported to be responsible for the increase in viscosity. ${ }^{28)}$ Ghiasi et al. ${ }^{11}$ showed that amylose was leached from untreated starch at temperatures below $95^{\circ} \mathrm{C}$. Yet previous leaching studies also showed that branched material was obtained at the higher temperatures. How does the structure/organization of the granule account for this behavior?

Retrogradation is an important property of gelatinized starches. Amylose retrogrades rapidly, forming a precipitate from dilute solutions and a gel from concentrated solutions. Eberstein et $a l^{29)}$ reported differential scanning calorimetry data for retrogradation of both amylose and amylopectin. Amylopectin apparently is the starch component which undergoes slow retrogradation in food (starch) systems when water is limited. This behavior has been implicated in the staling (firming) of bread with time. ${ }^{30,31)}$ Matsukura et al. ${ }^{32}$ proposed a possible structure for retrograded starch (Fig. 7) involving amyloseamylose, amylose-amylopectin and amylopectinamylopectin associations. How does the struc-

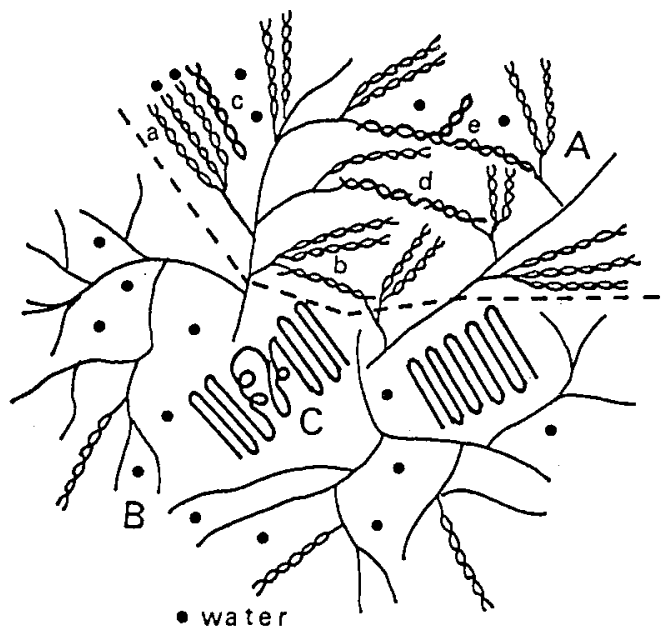

Fig. 7. Possible structure for retrograded starch.

Reproduced from Ref. 32).

ture of partially gelatinized starch, particularly in water limiting systems, account for retrogradation? What are the relative roles of leached amylose, leached branched-chain material, amylopectin within granule remnants, and amylose/ amylopectin at the granule boundary in retrogradation and in the rate of retrogradation in food systems? Does retrogradation play a role in the firming of starch gels or food systems such as bread?

\section{CONCLUSION}

This has been only a progress report on the road to understanding the structure of starch and the role of structure in the physical and functional properties of starch. I am deeply honored by the recognition you have accorded me, particularly when I look at others who have been recognized by this award. I have been fortunate to include Drs. Nikuni and French among my friends and have experienced the impact they made on the field we love. To paraphrase an American poet: The granule is dark and deep, but we have years to go and questions to ask before its secrets we keep. There are many challenging, exciting questions which remain to be solved before we can relate the structure of starch (amylose, amylopectin, granule) to functionality. 


\section{REFERENCES}

1) R. H. HARRIS: Bakers Digest, 16(4), 217 (1942).

2) R. M. SANDSTEDT: Bakers Digest, 35(3), 36 (1961).

3) R. C. Hoseney, K. F. Finney, Y. PomeranZ and M. D. ShOGREn: Cereal Chem., 48, 191 (1971).

4) D. R. LiNEBACK: Bakers Digest, 58(2), 16(1984).

5) P. Colonna and C. Mercier: Carbohydr.Res., 126, 233 (1984).

6) S. Peat, S. J. PirT and W. J. Whelan: J.Chem. Soc., 705 (1952).

7) C. T. Greenwood and J. Thomson: J. Chem. Soc., 222 (1962).

8) K. Ghiasi and R. C. Hoseney: Stärke, 33, 428 (1981).

9) S. HizUKURI, Y. TAKEDA, M. YASUdA and A. SuzUKI: Carbohydr. Res., 94, 205 (1981).

10) C.-Y, LII, S.-M. CHANG and R. W. Jou: in Program \& Abstracts, 44 th Annual IFT Meeting, Anaheim, CA., Abstract No. 89 (1984).

11) K. GHiasi, R. C. Hoseney and E. VARrianoMARSTON: Cereal Chem., 59, 81 (1982).

12) K. H. Meyer and P. Bernfeld: Helv. Chim. Acta, 23, 875 (1940).

13) Z. NikUni: J. Sci. Cookery, 2,6 (1969).

14) Z. NIKUNI: Stärke, 30, 105 (1978).

15) D. FrenCH: J.Jpn. Soc. Starch Sci., 19, 8(1972).

16) J. P. Robin, C. MERCIER, R. CHARBonNiere and A. Guilbot: Cereal Chem., 51, 389 (1974).

17) D. J. MANners and N.K. MATHEson: Carbohydr. Res., 90, 99 (1981).
18) J. J. Marshall and W. J. Whelan: Arch. Biochem. Biophys., 161, 234 (1974).

19) C.-Y. LiI and D. R. LineBACK: Cereal Chem., 54, 138 (1977).

20) W. A. Atwell, G. A. Mrlliken and R. C. HoSENEY: Stärke, 32, 362 (1980).

21) S. KobAYASHI, S. J. SchWARTZ, and D. R. LiNeBACK: Cereal Chem., In press.

22) S. Kobayashi, S. J. SchWARTZ and D. R. LiNeBACK: J. Chromatogr., 319, 205 (1985).

23) A. Meyer: in Untersuchung über die Starkekorner, Gustav Fischer, Jena, (1895).

24) S. A. S. CRAIG and J. R. STARK: Carbohydr. Res., 131, 117 (1984).

25) K. Kainuma: Chori Kogaku, 13, 83 (1980).

26) D. FrenCH: in Starch: Chemistry and Technology, 2nd ed., R. L. Whistler, J. N. BEMiLleR and E.F. PAschall, eds., Academic Press, New York, p. 184 (1984).

27) B. M. Gough and J. N. PyBus: Stärke, 23, 210 (1971).

28) B. S. Miller, R. I. Derby and H. B. Trimbo: Cereal Chem., 50, 27 (1973).

29) V.P. Eberstein, R. HopcKe, G. KonieczNyJANDA and R. STUTE: Stärke, 22, 397 (1980).

30) R. J. SCHOCH and D. French: Cereal Chem., 24, 231 (1947).

31) S. K. KIM and B. L. D'APpoloniA: Cereal Chem., 54, 216 (1977).

32) U. Matsukura, A. Matsunaga and K. KainuMA: J. Jpn. Soc. Starch Sci., 30, 106 (1983). 